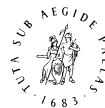

B R I L L
IAWA Journal 41 (1), 2020: 1

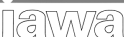

Editorial

\title{
The start of a new era
}

With issue 1 of Volume 41 of the IAWA Journal we start a new era with two new editors in chief, an expanded team of associate editors and a move to the new standardised Brill format with a new font, some minor changes in format and a slightly different size for the printed journal. Together with our improved impact factor which puts the IAWA Journal at the top ranking among wood science journals, the new decade is looking promising for publishing in wood anatomy. With support from authors and referees we hope things will improve even further for our journal in the coming years. Retiring editors in chief Pieter Baas and Elisabeth Wheeler will continue to act as associate editors. With the retirement of our desk editor Emma van Nieuwkoop, the journal will be skilfully edited by Marc Jarmuszewski and the editorial team at Brill in Leiden.

To briefly introduce the new editors in chief.

Lloyd Donaldson is a senior scientist at Scion in Rotorua, New Zealand. Starting work in 1980 as wood anatomy technician, Lloyd has amassed 40 years of experience in wood identification, as well as scientific studies on wood ultrastructure, wood formation and wood structure/properties relationships. With over 120 journal articles and book chapters as well as many years as associate editor for IAWA Journal and as reviewer for wood science, botanical and microscopy journals, Lloyd has extensive editorial experience.

Marcelo Pace has just started a tenure track at the National Autonomous University of Mexico. Being originally from Brazil, he completed his $\mathrm{PhD}$ at the University of São Paulo under the mentoring of Veronica Angyalossy, IAWA long standing member. For the past 1o years he has been researching wood and bark anatomical evolution, exploring the links between ontogeny and phylogeny to unravel the formation of complex cambial variants. In the IAWA he has co-edited the IAWA Bark List and represented the Association in several congresses. 